\title{
Construction and Integration of Teacher's Empowerment Images
}

\author{
Shun-Ho Wang ${ }^{1, a}$ \\ ${ }^{\text {IS }}$ chool of Education Science, Zhaoqing University, Zhaoqing Avenue, Duanzhou District, Zhaoqing City526061, \\ Guangdong Province, China \\ ${ }^{a}$ Email:168868626@qq.com
}

\begin{abstract}
This study uses a dynamic "process model" to explore the construction of teacher's empowerment images from internal and external processes. The purpose of this study is to explore the construction types of teacher's subjective and objective empowerment images, as well as the interaction and integration between the two. The external stimulation process is also called "structural empowerment", which includes objective and external situations and interpersonal interaction factors. The internal transformation process is also a micro "psychological empowerment", which includes self-awareness and experience construction. The development of teacher empowerment takes place in these two internal and external processes, forming a dynamic and cyclic interactive relationship, which unify and construct the image of teacher's empowerment images.
\end{abstract}

Keywords: Empowerment, Process model, Structural empowerment, Psychological empowerment

\section{INTRODUCTION}

The concept of empowerment has been around for over 50 years and is not a new research topic. Brazilian educator Paul Freire promoted this concept in the field of education in the late 1960s and early 1970s. Its main connotation includes two angles of enhancing power and ability, that is, increasing external power and benefiting internal ability. In short, it refers to the status and autonomy of teachers, as well as the reflection and growth of teaching.

Teacher empowerment has been at the core of education reform since the early 1980s. It is regarded as the result of the reform [1]. This study adopts a dynamic "process model" to explore the internal and external development of teacher empowerment, observe the influencing factors of teacher empowerment, and analyse the construction types of teacher subjective and objective empowerment images, as well as the interaction and integration between them, as shown in Figure 1.

\section{EXTERNAL CONSTRUCTION--. STRUCTURAL EMPOWERMENT}

Teacher empowerment can be divided into external "structural empowerment" and internal "psychological empowerment" in terms of its motivation sources [2].
These two dynamics initiate the internal and external processes of teacher empowerment. Among them, "structural empowerment" starts the external process of teacher empowerment, it refers to environmental factors such as opportunity, information, resources and support that can be provided for individuals to promote their professional empowerment [3].

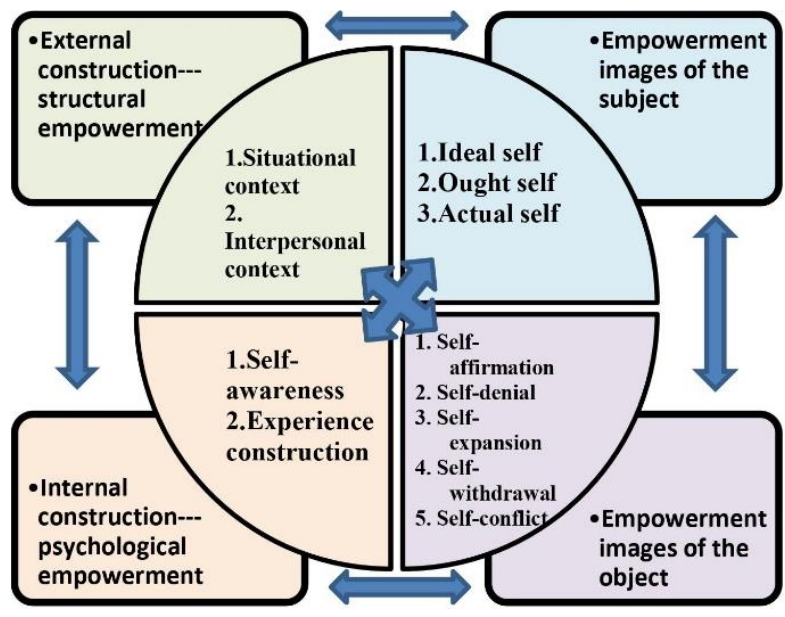

Figure 1 The interaction of construction factors of teacher's empowerment images.

Under the top-down organizational structure and policies, empowerment is seen as a management measure 
for schools to share the power of teachers. However, in addition to this, all external factors contributing to teacher empowerment are considered "structural empowerment" in this study. Therefore, the external process in this study includes objective and external situations and interpersonal interaction factors.

\subsection{Situational context}

The external approach of structural empowerment mainly includes the situational context and the interactive interpersonal context. The external situational context includes six aspects: international education trend, social environment and culture, educational legal structure, role orientation, information exchange platform, and personal growth background. The interactive interpersonal context includes administrative supervisors at all levels in the school, peers, students, community partners, and family and friends.

These factors that influence teacher empowerment are often different according to people, times and places, and these differences will result in the diversity of empowerment images. Because teacher empowerment is a dynamic change, there will be different choices with different background, level and context.

Teacher empowerment emphasizes not only the individual level, but also the level of social and other relationships. Therefore, it cannot be explained in a single, fixed, micro view of empowerment, but rather needs to maintain a flexible and diverse perspective of thinking.

\subsection{Interpersonal context}

The interpersonal context is derived from the concepts of psychology and sociology. "Significant others" who have important influence in the process of socialization and the formation of personality. In order to get approval from "significant others", individuals will accept their values to develop themselves and interpret the outside world. "Significant others" play a key role in each person's growth, and even influence his career choice.

In the construction process of teacher empowerment, "Significant others" are also the objects that teachers must contact. They are usually supervisors at all levels in the school, peers, students in the class, community partners, family members and friends. These people play the role of helper, oppressor, partner, or adversary in the process of teacher empowerment. Therefore, this study defines the "significant others" in the interpersonal context as informal structural empowerment factors.

\section{INTERNAL CONSTRUCTION--- PSYCHOLOGICAL EMPOWERMENT}

"Psychological empowerment" is a micro approach that focuses on individuals' perceptions or attitudes towards their roles in organizations. Empowerment is seen as an intrinsic motivator [4]. It emphasizes the individual's inner experience of empowerment and the process of changing the individual's inner beliefs [5]. This study regards it as the construction of individual inner psychology and experience empowered by teachers, including self-awareness and experience construction

In short, the "psychological empowerment" of teachers starts from the inner motivation of the individual, emphasizing the inner experience of empowerment, and at the same time paying attention to the process of changing the construction of the individual's inner belief and experience.

\subsection{Self-awareness}

According to the development level of self-awareness, self-awareness can be divided into three main types, they are "simple conscious awareness", "reflective selfawareness" and "reflexive self-awareness" [6].

The development of these three elements implicit a dialectical form of "positive, negative and combined", from "simple conscious awareness" (I know what I am doing), to "reflective self-awareness" (I know how well I am doing), and finally "reflexive self-awareness" (I know I'm doing what I'm doing). The next stage is the dialectical result of the last stage, and the last stage is the dialectical basis of the next stage. In the dynamic process of continuous dialectical development, the true-self can be gradually recognizable.

\subsection{Experience construction}

Radical constructivism believes that the knowledge of the construction of personal subjective experience comes from the activities or processes of personal experience, which rationalizes or makes practical experience. The experience construction of teacher empowerment is carried out according to different levels of the development of self-awareness, including the activities and processes that teachers actually participate in, and obtain reasonable or practical experience.

However, no matter what the level of self-awareness development, the construction of teacher empowerment experience must be interacted within the scaffolds of selfprior experience, situational context, and interpersonal context. Personal prior experience refers to the values, thinking and reaction patterns that are memorized, learned, and accrued during the growth of an individual. Its connotation can be divided into four levels of personal experience, family experience, social experience and 
cultural experience according to the relationship or phenomenon field in which the individual is placed [7].

The development of teacher empowerment takes place between the internal process of perception and experience construction and the external process of situation and interpersonal context. Teachers' internal perception and experience construction are the core of the process of empowerment transformation, but they are interrelated with external motivating factors. Teacher's self-awareness presents a dialectical form of "positive, negative and combined", which continuously develops dialectically in the three levels of "simple conscious awareness", "reflective self-awareness" and "reflexive self-awareness".

\section{CONSTRUCTION AND INTEGRATION-- TEACHERS EMPOWERMENT IMAGES}

Based on the degree and outcome of their selfawareness, teachers begin to increasing external power and benefiting internal ability in the three scaffolds of the self-prior experience, situational context, and interpersonal context. Teachers create five aspects of experience and value: participation decision, professional autonomy and authority, professional growth, selfefficacy, and professional knowledge and ability. Then, they construct the whole empowerment images of teacher, including subjective and objective empowerment image.

\subsection{Empowerment images of the subject}

The "empowerment images" is not a single concept, but overall perception to multi-level structure. In general, the subject of teacher's empowerment images has three levels: "ideal self", "ought self" and "actual self". "Ideal self " is a concept of gestalt. In addition to helping students to pursue affirmation and goals, teacher's "ideal self" concept should also have the critical ability to examine the structure of educational situation, so that teacher does not become a mere tool and neglect the moral power.

"Ought self" is the teacher's self-evaluation and standardization of professional power and ability, which makes the teacher think that he or she should be or feel obligated to be the representation of professional power and ability. Therefore, the teacher will strengthen teaching knowledge and ability, carry out academic research continuously, and actively prepare for teacher qualification promotion, so that he or she can become a teacher with professional power and ability standards.

The "actual self" is the external representation of the teacher's professional power. According to the guidance of the "ideal self" and " ought self ", the "actual self" is the overall performance of the actual action towards the representation of the professional power that the teacher wants to be, should be, or feels obligated to be. Therefore, the degree of congruence between "actual self", "ideal self" and "ought self" affects the teacher's empowerment images and determines his external performance.

\subsection{Empowerment images of the object}

Empowerment images of the object are a kind of socialization process and product, which is the interaction result of teachers in various social contexts and interpersonal relations. It is the empowerment images formed by "significant others" in the context of teachers' awareness of international education trend, social environment and culture, educational legal structure, role orientation, information exchange platform, and personal growth background.

Empowerment images of the object are produced between "seeing" and "being seen". It is formed through the interaction with others, others' views of oneself, put oneself in the position of others and reflect oneself Therefore, the views of oneself is the reflection of others views of oneself. The empowerment images change with the level of awareness. The reference framework of selfevaluation is derived from peers and society. Individuals develop their self-concept through continuous selfevaluation in different contexts. Successful experiences enhance an individual's self-concept, while unsuccessful experiences may elicit strong emotional responses that undermine the self-concept [8].

Therefore, the image of the object fits the point of view of the symbolic interactionism in psychology. Mead and Cooley of the Chicago School of Psychology put forward this important theory, and they paid special attention to the development of social interaction and selfconception. Cooley (1902) put forward the concept of "looking glass-self", he believes that "significant others" form a "social mirror", through which "significant others" affect the construction of the self [9].

The formation of self-concept is through the communication with others, in the interaction with each other, imagine their image in the eyes of others, and then stand in the perspective of others may think about the image of others, and gradually generate a sense of self.

However, what are the types of the empowerment images of the object to provide us with objective observations? Scholars have proposed different classifications based on different attributes, aspects, connotations and hierarchical structures. These numerous classifications often interpret objects into different images, which are dazzling and disorienting.

This study focuses on the basic elements of image formation, and divides the teacher's empowerment images into five basic types, including self-affirmation, selfdenial, self-expansion, self-withdrawal, and self-conflict, according to the context of teacher's situation and 
interpersonal interaction. The five basic types belong to pure types, and individuals cannot only present a single type. Each type is combined and coexists in different proportions. When the type with a large proportion will form the significant individual characteristics, it will be classified accordingly.

\section{CONCLUSION}

The teacher's understanding of his own empowerment images is the result of the internalization of others' views of him. The empowerment images of the subject constructed through self-awareness and introspection will also determine the evaluation of the empowerment images of the object. The two are inextricably related, they are each other's cause and effect and each other's process.

Although the interaction between the internal and external empowerment processes is very subtle and changeable, and the construction of relevant theories is still under development, this study explores the correlation and interaction between the connotation of images, the construction process and influencing factors of teacher empowerment, and tries to put forward the following five concepts:

- Teacher's empowerment images are the multidimension hierarchical structure. In this multidimensional hierarchical structure, the subjective "ideal self" is at the top and the "actual self" which is the basis of self-image construction is at the bottom. In the process of moving from the bottom to the top, the connotation of self-image will become more complex and diversified due to the addition of different construction factors of objectification, forming a dynamic and cyclic process of mutual influence.

- The core of the empowerment images of the subject is subjective perception, evaluation and attitude about teacher, because the empowerment images of the object are often influenced and guided by the subject's selfawareness.

- As the empowerment images of the object come from the process and product of socialization, they become a dynamic reference framework for teacher's self-awareness. When individuals observe and feedback the context of objective situations, they provide information necessary for the construction of the empowerment images of the subject.

- The positive or negative development of the interaction between the subjective and objective empowerment images can be understood from the degree of difference in self-awareness.
When inner awareness and external awareness both produce gap, the empowerment images of the subject and the object fall into negative development, and then form a self-denial, selfexpansion, self-withdrawal, and self-conflict. This situation will induce individual negative emotions and ultimately fails to construct a complete and unified the empowerment images.

- The cognitive differences of "ideal self", "ought self" and "actual self" in the empowerment images of the subject can be used to explain the characteristics and connotations of the five basic types of objectified images.

\section{REFERENCES}

[1] Usha Mishra \& Yogesh Mishra, Teacher's empowerment: A need for making excellent in academics. International Referred Research Journal, 1(17), 2011, pp.34-35.

[2] Sarminah Samad, Social Structural Characteristics and Employee Empowerment: The Role of Proactive Personality. International Review of Business Research Papers, 3(4), 2007, pp. 254-264.

[3] A. Hauck, M. T. Quinn Griffin \& J. Fitzpatrick, Structural empowerment and anticipated turnover among critical care nurses. Journal of Nursing Management, 19(2), 2011, pp.269-276.

[4] J. A. Conger \& R. N. Kanungo, The empowerment process: Integrating theory and practice. Academy of Management Review, 13(3), 1988, pp.81-105.

[5] K. W. Thomas \& B. A. Velthouse, Cognitive elements of empowerment: An interpretive model of intrinsic task motivation. Academy of Management Review,15(4), 1990, pp.666-681.

[6] M. E. Kondrat, Who is the "self " in self-aware: Professional self-awareness from a critical theory perspective. The social service review, 73(4), 1999, pp.451-478.

[7] W. B. Gudykunst \& Y. Y. Kim, Communicating with strangers: An approach to intercultural communication. MA.: Addison-Wesley, 1984.

[8] Zhao xiaomei. The development and change strategies of self-concept. Journal of Taiwan Educational Development Forum, 1, 2010, pp.31-53.

[9] C. H. Cooley, Human nature and social order. North Highlands, CA: Best Books, 1902. 